\section{GSR Journal}

Georgetown Scientific Research Journal
Volume 1 | Edition 2

\section{July 31, 2021}





\section{The Burn Behind the Bullet: \\ Understanding Black Mothers' \\ Experiences After Losing a Child to Gun Violence in Washington, DC-Baltimore City Metropolitan \\ Region}

Denzell Brown 


\title{
The Burn Behind the Bullet: Understanding Black Mothers' Experiences After Losing a Child to Gun Violence in Washington, DC-Baltimore City Metropolitan Region
}

\section{Denzell Brown}

Department of Psychology and African American Studies, Georgetown University, Washington D.C. E-mail: dob15@georgetown.edu

https://doi.org/10.48091/gsr.v1i2.20

\begin{abstract}
The purpose of this research article is to examine how complicated grief, post-traumatic stress, and depressive symptoms induced from losing a child to gun violence affect traits of resilience and posttraumatic growth among a sample of Black mothers living in Washington DC and Baltimore, Maryland. This research project was executed by surveying 4 Black mothers who lost a child to gun violence (B.M.C.G.V.) that resided in the Baltimore-Washington area to assess grief, traumatic stress, and depression. Participants also completed an oral interview that focused on resilience, post-traumatic growth, and policy recommendations. Findings associated with post-traumatic stress indicated that all Black mothers in this study reported it was somewhat true that they avoid things that remind them of their loved ones $(n=4,100 \%)$, and 3 out of 4 of the mothers felt cut off or distant from other people since their loved one died $(n=3,75 \%)$. Outcomes related to complicated grief revealed that all mothers in this study reported that they felt a great deal of loneliness since their child had died $(n=4,100 \%)$. Moreover, 3 out 4 B.M.C.G.V. reported that memories of their child made them upset in the last past 7 days $(n=3$, 75\%). Results aligning with post-traumatic growth displayed that all Black mothers in this study reported it was mostly true that they learned they were stronger than they originally thought they were after losing a child to gun violence $(n=4,100 \%)$. Additionally, 3 out of 4 Black mothers in this study stated that it is mostly true that they developed a strong religious faith upon losing a child to gun violence $(n=3,75 \%)$. Furthermore, 3 out of 4 Black mothers in this study reported that they found a stronger sense of purpose in life upon losing a child to gun violence $(n=3,75 \%)$. Findings related to depressive symptomatology contained a large amount of variation and did not produce any significant results. The data results from the oral interview indicated that 9 common characteristics emerged from Black mothers who lost a child to gun violence in this study which included Black mothers explaining their character traits as Loving, Committed, and Strong. Subsequently, Black mothers classified their coping strategies as Active Coping (Embracing Self-love, Forgiveness, and Faith in God) and Avoidant Coping (Denial, Betrayal, and Not Coping). Lastly, Black mothers' policy recommendations in this study focused on themes such as Demanding resources and Laws on gun violence prevention.
\end{abstract}

Keywords: complicated grief, post-traumatic growth, gun violence 


\section{Introduction}

Throughout the United States of America, a disproportionate number of Black youths become homicide victims of gun violence annually, and every year Black mothers nationally have to deal with the psychological consequences of the death of their own child. To date, much of the research on gun violence in predominantly Black communities tend to focus on African American male-identified youth. Yet, there is a large amount of literature that indicates B.M.C.G.V. experiences compounding levels of trauma, complicated grief, and depression. For instance, Black mothers experience various incarnations and manifestations of racism and sexism. ${ }^{1}$ Given that Black mothers' experiences with gun violence are impacted by racial-gendered stereotypes, African American mothers are also consequently labeled as being "strong Black women." The discourse of being "strong" tends to normalize distress inducing levels of selflessness and powerlessness among AfricanAmerican mothers. ${ }^{2}$ Therefore, Black mothers face the multiplying effects of racism and sexism while simultaneously experiencing forms of complicated maternal grief that emerge from losing a child to gun violence. Maternal grief is considered to be the most persistent and profound grief. $\underline{3}$ In the process of Black mothers navigating maternal grief, African American mothers may also feel a sense of injustice associated with their child's death, as well as experience symptoms of complicated grief due to multiple past and present traumas..$^{4}$ As shown, prior research suggests that Black mothers who lose children to gun violence experience posttraumatic stress, complicated grief, and depressive symptomatology.

On a spectrum, Blacks mothers encounter multi-layered levels of psychological stress that derive from losing a child to both civilian and police gun violence. Considering that a large number of Black mothers lose children to police gun violence, African American mothers of color also often feel betrayed by law enforcement and the criminal justice system. ${ }^{4}$ Furthermore, African American mothers are also often traumatized daily by the sudden loss of their loved ones and re- traumatized by the news of another murder in the country. ${ }^{4}$ As a protective barrier to cope with the complicated grief that absolves from losing a child to gun violence, Black mothers appear to demonstrate a sense of resilience in childbearing after the loss. ${ }^{4}$ Black mothers tend to embody resilience by relying on solidarity and collective survival through community mothering practices that have been characterized as Black 'activist mothering.' The practice of Black 'activist mothering' allows for African American mothers who lost a child to gun violence to manage their experiences with complicated grief by having a public space to share grief and conceptualize healing. $\frac{5}{}$ In cases where Black mothers pursue a journey of healing, some Black mothers embrace post-traumatic growth as a method to augment the traumatic stress associated with losing a child to gun violence. As referenced in a recent mixedmethods study on Black low-income mothers who survived Hurricane Katrina, catastrophic losses in some cases create spaces for post-traumatic growth for survivors. $\frac{6}{}$ Therefore, the goal of this research paper will be situated on illustrating B.M.C.G.V. coping mechanisms, healing methods, and posttraumatic growth qualities.

\subsection{Depressive Symptomatology}

Depressive symptomatology can be expressed through a range of different emotions including constant feelings of sadness, emptiness, restlessness, guilt, and social isolation. ${ }^{\underline{7}}$ According to King-Hannays et al 2013, Black mothers' bereavement experiences upon losing a child to gun violence often impact this population's ability to maintain social relationships. The results of this study revealed that there was an association between Black mothers whose children were homicide victims and mothers who experienced altered relationships within their family-friend networks (directly correlated with feelings of isolation and sadness).. that Black mothers who have lost a child to gun violence endure can be characterized by intrusive thoughts about the deceased, a subjective sense of numbness, detachment or absence of emotional 
responsiveness, searching for the deceased, and loneliness as a result of the death. ${ }^{4}$

\subsection{Post-Traumatic Stress}

Post-traumatic stress can be characterized by the avoidance of thoughts and activities associated with traumatic events and can result in a constant state of hypervigilance. $\frac{9}{}$ The experience of losing a child to gun violence is a traumatic event that can result in a variety of distressful emotions such as meaningless and devastation which can lead to debilitating traumatic stress. ${ }^{10}$ Research on posttraumatic stress identifies the death of a child as the most severe stress encounter for parents. ${ }^{11}$ Specifically for Black mothers who lost a child to gun violence, death-related traumas were an ongoing source of fear and pain. ${ }^{4}$ The ongoing fear and pain that Black mothers experience are related to grief and rumination about the causes and consequences of the loss. $\frac{12}{}$

\subsection{Complicated Grief}

Complicated grief may include symptoms like severe pangs of emotions, denial of implications of the loss to the self, and neglect of necessary adaptive activities. $\frac{13}{}$ Grieving a violent death is different from a normal or uncomplicated bereavement behavior as the difference in the death is caused by human intent or negligence. ${ }^{10}$ Therefore, disturbed or complicated grief can be understood as a condition that arises when the normal progression of grief does not occur. ${ }^{13}$ Due to the life-altering experience of losing a child to gun violence, Black mothers experience prolonged feelings of pain and detachment from others which ultimately heightens the emotional presence of complicated grief. There is a direct correlation between B.M.C.G.V. and Black mothers' reported experiences of complicated grief. For instance, according to a recent study by Burke et al 2010, which investigated African Americans' processing of homicide bereavement in Memphis Tennessee, findings reveal that Black mothers reported bereavement outcomes such as complicated grief, PTSD, and depression. $\frac{15}{}$ The complicated grief, post-traumatic stress, and depressive symptoms that B.M.C.G.V., also often encourage Black's mother's to independently search for effective ways and alternative strategies to understand the death of their child. Furthermore, prior research suggests that throughout the process of navigating effective ways to understand their children's death, that Black mothers also demonstrate resilience and self-coping strategies.

\subsection{Resilience}

Black mothers that are grieving the death of their children often develop resilience and coping strategies by relying on social networks and appraising positive meaning to the occurrence of death. Based on the Bailey et al 2013 study, which examined B.M.C.G.V. in Canada, social support and assigning a positive meaning to the death of one's child mediated the effects of post-traumatic stress that Canadian Black mothers experienced. Social support and positive appraisal as mediating factors ultimately played a role in increasing feelings of resilience among Canadian Black mothers within this sample that lost children to gun violence. ${ }^{11}$ This specific finding highlights how Black mothers that lose children to gun violence do not only experience depression, grief, and trauma, but also that they embody resilience and embrace self-coping mechanisms despite their traumatic experiences to affirm emotional sustainability.

\subsection{Post-Traumatic Growth}

Post-traumatic growth (PTG) consists of positive psychological changes that arise from experiencing new opportunities that come to light as a result of a traumatic experience, as well as through the cognitive and emotional processing of trauma-related thoughts, sensations, emotions and, memories. ${ }^{16,} 17$ Notably, multiple findings demonstrate that people identifying with oppressed identities - such as racial minorities or women - report higher PTG than those identifying with more privileged statuses. Given that Black mothers identify as a racial minority and are normatively classified as women, posttraumatic growth is a relational variable that 
applies to African American mothers who lost a child to gun violence. Research on the intersection of post-traumatic growth and gun violence in the Baltimore-Washington area claims that posttraumatic growth can be conceptualized as, how individuals work to reconcile their trauma with their religious beliefs and can strengthen those beliefs, lead to positive spiritual change, shifting priorities, and an appreciation for life posttrauma..$^{18}$ This classification of post-traumatic growth will serve as the working definition used to explain Black mothers' post-traumatic experiences after losing a child to gun violence in this article. In the context of the Baltimore-Washington DC region, some Black mothers' process of healing is marked by engagement with post-traumatic growth as means to cope with the trauma associated with the death of their child.

As shown, there is evidence throughout inner cities in the U.S and Canada that Black mothers experience psychological depression, posttraumatic stress, and complicated grief while mourning the death of their children who were homicide victims of gun violence. However, what has not been clarified in this area of research are the specific and intricate ways in which Black mothers develop resilience, coping mechanisms, and post-traumatic growth qualities in the process of grieving the death of their child. The specific ways that Black mothers develop resilience, embrace post-traumatic growth, and cope with the death of their children who are homicide victims has not been researched in-depth on a mass scale in the field of psychology, rendering their experiences invisible. Research surrounding this topic tends to solely focus on Black mothers' grief, depression, and psychological trauma in both of these major cities. While this is important, it leaves out possible moderating factors like resilience, coping, and post-traumatic growth that also characterizes Black mothers' lived experiences which, if identified, could provide policymakers and practitioners with levers for improving mental health services within Black communities throughout the Washington, DC, and Baltimore City metropolitan region.

\subsection{Current Study}

This study will seek to investigate Black mothers whose children have been homicide victims of gun violence throughout the BaltimoreWashington DC regions' emotional experiences of depression, complicated grief, and posttraumatic stress. Additionally, this study will also document these women's processes of formulating resilience, post-traumatic growth, and effective coping strategies. This research project aims to not only analyze the complicated grief, psychological depression, and posttraumatic stress that Black mothers face whose children were victims of gun violence but also to document Black mothers' independent self-coping strategies, methods of resiliency, and post-traumatic growth capabilities. Findings from this line of research will provide actionable steps for local policymakers and practitioners (social workers; community workers) to support the needs of Black mothers enduring the death of a child due to gun violence in the Baltimore- Washington, DC region.

\section{Methods}

\subsection{Research Design}

This study used a mixed-methods descriptive research design to examine how grief, posttraumatic stress, and depressive symptoms that are induced from losing a child to gun violence affect the variables of resilience and posttraumatic growth among a sample of Black mothers living in the Washington DC-Baltimore metropolitan area.

\subsection{Research Questions}

This study sought to examine three specific research questions which includes:

(1) How do Black mothers that have children who have been homicide victims of gun violence experience feelings of depression, grief, and posttraumatic stress?

(2) Do Black mothers who lose a child to gun violence embody characteristics that resemble variables of post-traumatic growth? 
(3) What coping strategies and forms of resilience do these mothers use or demonstrate that may be effective in mitigating the crippling effects of losing a child to violence?

\subsection{Hypotheses}

(1) Black Mothers in Washington DC who have lost a child to gun violence will exhibit emotional expressions of trauma, grief, and depression. (Independent variable $=$ gun violence; dependent variable = trauma, grief, depression)

(2) Black Mothers in this study will showcase high levels of self-sufficient coping mechanisms, posttraumatic qualities, and traits of resilience

\subsection{Sample}

The sample of this study includes a total of 4 Black mothers that are between the ages of 18-65 years old. All of the women involved in this study met the eligibility criteria of losing a child to gun violence and living in the Washington-DC and Baltimore city metropolitan area. To limit the possibility of emotional harm, participation in this study was restricted to only Black mothers in the Washington-Baltimore area who lost a child to gun violence 1 year or more prior to the start date of the study in December 2020. Demographic data in Table 1 shows Black mothers that participated in this study's occupation status and economic welfare dependence on public assistance. Furthermore, Table 1 also indicates the context under which the gun violence occurred, including the average age of the child when they passed away, if the individual(s) responsible for this death were identified, and whether the individual(s) responsible were law enforcement agents (Table 1).

Table 1: Participant child's age at death, knowledge of perpetrator(s), perpetrator(s) involvement with law enforcement, marital status, and dependence on welfare assistance

\begin{tabular}{|l|l|l|l|l|l|}
\hline Participant & $\begin{array}{c}\text { Child } \\
\text { Age } \\
\text { at } \\
\text { death }\end{array}$ & $\begin{array}{l}\text { Does the participant } \\
\text { know the individual } \\
\text { responsible for the } \\
\text { death of their child? }\end{array}$ & $\begin{array}{c}\text { Were individuals } \\
\text { responsible for the child } \\
\text { death police officers or law } \\
\text { enforcement agent(s)? }\end{array}$ & $\begin{array}{c}\text { Marital } \\
\text { Status }\end{array}$ & $\begin{array}{l}\text { Public Assistance food } \\
\text { stamps (SNAP), } \\
\text { Medicaid, housing } \\
\text { assistance, welfare } \\
\text { (TANF), etc? }\end{array}$ \\
\hline Participant 1 & 17 & Yes & Yes & Widowed & No \\
\hline Participant 2 & 14 & Yes & No & Married & No \\
\hline Participant 3 & 24 & Yes & Yes & Single & No \\
\hline Participant 4 & 29 & Yes & No & Single & No \\
\hline
\end{tabular}

\subsection{Recruitment and Data Collection}

Upon receiving approval from Georgetown University's Institutional review board, a multiplicity-network sampling method was used to recruit participants from several non-profit organizations and community grief support groups. Multiplicity or network sampling is a process by which individuals distribute recruiting information with neighbors, co-workers, and members of their community at large. Multiplicity sampling is best used for locating and measuring rare populations. $\frac{18}{}$ Using this sampling method, this study began with a target population of 2 Black mothers who completed the survey and interview portion of this research design after being referred by community mental healthcare providers and non-profit organizations leaders. The individuals and organizations featured in the initial target population of this study then shared recruiting materials such as flyers and the principal investigator's contact information with other women who met the eligibility criteria to participate in this research design. Given the griefprovoking nature of the content discussed during this study, all participants were provided with a phone number of a licensed grief therapist that specializes in trauma-informed violence interventions. Lastly, all participants were also provided with access to Washington DC's 
Department of Behavioral services mental health mobile hotline and Baltimore city's accredited crisis center's phone line.

\subsection{Measures}

To assess the demographic data of the population of Black mothers involved in this study participants were asked a series of self-reported survey questions regarding marital status, occupation, and public assistance income benefits. Marital status was assessed among participants by asking the question "What is your current marital status?" Participants occupation was investigated using the question "Are you currently working for pay, full or part-time?”. Income was determined by asking about participants' access to receiving public benefits using the question "Do you receive any public benefits like food stamps (SNAP), Medicaid, housing assistance, welfare (TANF), etc?" Lastly, to determine the context and occurrence of this sample of Black mothers' children's death, participants were asked about the age of the child at death, the individual(s) responsible for the death, and if this or these individual(s) were law enforcement agents. The questions used to obtain this information included "Please enter the age of your child or loved one were when they passed away", "Do you know the individual(s) who was responsible for the death of your child or loved one?", "Were these or these individuals police officer(s) or member(s) of law enforcement agencies?” (Table 1).

\subsubsection{Complicated Grief (9 Items)}

Questions measuring complicated grief among B.M.C.G.V. were drawn from the Prigerson, et al. 1995 Inventory of Complicated Grief (ICG) which measures feelings of sadness, anger, and disbelief on a 4-point Likert scale ( $0=$ never, 1 =rarely, 3 =sometimes, $5=$ Often). .19 The inventory of complicated grief asks questions such as "how often do you feel empty without the person who died?" and "how often do you feel bitter over this person's death?". The ICG's internal consistency, as reported by Prigerson, et al. (1995), was very good; the alpha coefficient was
94. The test-retest reliability was found in the same study to be 80 . In addition, this scale has a well-validated clinical cut point. $\underline{20}^{2} \underline{19}$

\subsubsection{Post-Traumatic Stress (5 Items)}

To document the post-traumatic stress that B.M.C.G.V. experienced this study used the Daniel S. Weiss. Revised Trauma Impact Event Scale which captures the amount of stress that individuals associate with traumatic events on a 3point Likert scale (1=somewhat true, 2 = mostly true, 3 = Very much true.) Items on the ImpactEvent scale seek to capture characteristics of intrusion and avoid avoidance. ${ }^{21}$ Sample questions from this scale include: for example, "How much trouble are you having/have you had accepting the death of __ ?) and (ex: "How much do you avoid things that remind you of your loved one?). The internal consistency of intrusion and avoidance on Daniel S. Weiss Revised 2007 event scale was acceptable (Cronbach's, alpha for intrusion $=0.79$, for avoidance $=0.82$ ). The test-retest reliability was satisfactory, with coefficients of 0.87 for intrusion and 0.79 for avoidance..$^{21}$

\subsubsection{Depressive Symptomatology (1 Item)}

One item was used to assess depressive symptomatology present among B.M.C.G.V. This was a specific yes or no depression screening question that asked, "during the last month have you had a period of 2 weeks or more when nearly every day you felt sad, empty, or depressed for most of the day or you lost interest in most things like work, hobbies, and other things you usually enjoy?". This question was derived from Georgetown University's Professor Dr. Anna D. Johnson prior research on depression among parents.

\subsubsection{Post-Traumatic Growth (4 Items)}

To record post-traumatic growth among B.M.C.G.V. in this study use Tedeschi \& Calhoun 1996 post-traumatic growth inventory. The Posttraumatic Growth Inventory measures 
positive outcomes reported by individuals who have undergone a traumatic event on a 4-point Likert scale ( $1=$ Not true about me, $2=$ A little true, 3 = Somewhat true, 4= Mostly True). This scale includes items such as, "I have a stronger sense of religious faith, I discovered I am stronger than I thought I was, etc". The internal consistency of the resulting 21-item Post-traumatic growth inventory is $\mathrm{a}=.90$. The test-retest reliability for the 21-item FTGI was acceptable at $r=.71 . \underline{16}$

\subsubsection{Resilience and Coping Strategies (3 Items)}

Using a qualitative interview approach, this study interpreted the resilience of B.M.C.G.V. and their self-coping strategies through a narrative analysis methodology with a topical story focus. A narrative analysis helps focus on the events and experiences that shape a person's selfunderstanding. $\frac{22}{}$ Topical stories are about a particular event or specific character. $\underline{23}$ In the context of this study, Black mothers were centered in the analysis and the event of losing one child to gun violence was captured as the particular event. Throughout an oral interview, Black mothers were asked 3 specific questions which include " 1 . If you could describe yourself as a mother in one word, what would it be? 2. How did you cope, understand, or make meaning of the death of your child? 3. Taking into account that you endured the experience of losing a child to gun violence, what political policy(s) would you like to see reflected to possibly aid yourself or anyone else in this position?". These questions were used to situate Black mothers at the forefront of documenting their own experiences considering that narratives are extremely helpful in gaining an understanding complex topics about which little is known. ${ }^{24}$

\subsection{Procedure}

Participants who met the inclusion criteria of being a Black mother who lost a child to gun violence in the Baltimore-Washington area 1 year or more prior to the start date of the study in
December 2020 were scheduled to complete the survey and interview portion of this study. Prior to beginning the study, Black mothers were given a detailed-written summary explaining the purpose of the research project along with an informed consent signature component that asked for participants' permission to participate in the study. Given the COVID-19 pandemic restrictions, Black mothers that agreed to participate in this study were given the consent form and online survey information via email or text and completed the survey via zoom video call or telephone. To control for social desirability bias reporting among participants before completing the self-reported survey the principal investigator re-assured participants that all survey results will be completely confidential and free of judgement. Additionally, participants were not informed or notified of which survey items corresponded to the topics being evaluated such as post-traumatic stress, complicated grief, or depression in order to further reduce the likelihood of reporting bias and experimenter effects. As participants began the survey, they were notified that their responses will be completely anonymous and no identifying information would be collected such as (i.e. last names, addresses, birthdates, etc.). Participants completed the online self-reported questionnaire survey with their cameras and microphones off and were informed if they had any questions that participants may unmute themselves to ask the principal investigator for assistance.

Upon completing the survey, participants were then welcomed to engage in an oral interview with the principal investigator. To ensure safety measures in the light of social distancing guidelines, participants completed the oral interviews via phone call or using the online zoom video platform. The oral interview began with a Greeting and Brief introduction of the Principal Investigator's name and reason for doing the research. The principal investigator then proceeded to inform the participants of their rights to confidentiality, described how the interviews will not be recorded, and explained that if at any 
time mothers felt uncomfortable or were unwilling to answer any interview question, the participant may choose not to answer questions or discontinue their participation in the study. Participants were then guided into a narrative discussion focusing on the 3 qualitative items and prompted to take as much time as needed to assess and fully answer each question contingent upon their comfortability. After participants completed the oral interview, each participant was thanked for their participation and offered a complimentary $\$ 30$ Safeway gift card.

\subsection{Analytic Strategy}

Given the small sample size of this study, the survey data were analyzed using basic descriptive statistics. Therefore, the most frequently reported information that Black mothers selected on the self-reported measure were organized by total and calculated into percentage values. The use of percentage values was the most cohesive and efficient quantitative analysis that can be used to showcase the data outcomes of B.M.C.G.V. reported experiences with post-traumatic stress, complicated grief, depressive symptomatology, and post-traumatic growth.

The oral interviews were analyzed and transcribed using a qualitative inductive thematic analysis. An applied inductive thematic analysis is a process that includes comparing and analyzing concepts found within participants' narratives, for the purpose of identifying central themes that helped to explain grief and coping strategies. ${ }^{4}$ The raw transcript data was imported into the Dedoose qualitative-mixed methods software and then analyzed by identifying emerging themes from participants' responses. Table 2 summarizes the responses participants provided to the qualitative oral interview items and the themes/sub-themes that emerged in the data.

\section{Results}

The results from the inductive thematic analysis indicated that 9 themes emerged from B.M.C.G.V. oral interviews. These 9 themes will be listed and discussed in the next few sentences. For qualitative item 1 which assessed Black mothers character traits, themes such as Loving, Committed, and Strong were prevalent. On qualitative item 2 which documented Black mothers' experiences with coping and resilience, the themes of: Active Coping (Self-love, Forgiveness, Faith in God) and Avoidant Coping (Denial, Betrayal, and Not Coping) were shown directly. Lastly, qualitative item 3 that focused on Black mothers' policy recommendations themes like Demanding Resources for Families and Laws on Gun Violence Prevention that give attention to the victims emerged from the data (Table 2). 
Table 2: Qualitative themes of resilience and coping strategies.

\begin{tabular}{|c|c|c|}
\hline Question & Theme & Direct Quote \\
\hline \multirow[t]{3}{*}{$\begin{array}{l}\text { Q1: If you could describe yourself as a } \\
\text { mother in one word, what would it } \\
\text { be? }\end{array}$} & Loving & $\begin{array}{l}\text { Participant 1: "Loving" } \\
\text { Participant 4: "Unconditionally loving" }\end{array}$ \\
\hline & Committed & Participant 2: "Committed" \\
\hline & Strong & Participant 3: "Strong" \\
\hline \multirow[t]{10}{*}{$\begin{array}{l}\text { Q2: How did you cope, understand, or } \\
\text { make meaning of the death of your } \\
\text { child? }\end{array}$} & $\begin{array}{l}\text { Active Coping } \\
\text { Self-love }\end{array}$ & $\begin{array}{l}\text { Participant 1: "embracing self-love and self-care } \\
\text { using meditation/yoga" }\end{array}$ \\
\hline & Forgiveness & $\begin{array}{l}\text { Participant 1: "learning to pursue } \\
\text { forgiveness to turn purpose into" }\end{array}$ \\
\hline & Faith in God & Participant 3: "greater faith in God" \\
\hline & $\begin{array}{l}\text { Avoidance coping } \\
\text { Denial }\end{array}$ & $\begin{array}{l}\text { Participant 4: "felt denial things were in slow } \\
\text { motion" }\end{array}$ \\
\hline & Betrayal & Participant 1: "initially feeling of \\
\hline & Lack of coping & Participant 2: "I did not cope" \\
\hline & $\begin{array}{l}\text { Laws on gun violence } \\
\text { prevention and centered }\end{array}$ & $\begin{array}{l}\text { Participant 4: "prevent guns from getting on the } \\
\text { streets" }\end{array}$ \\
\hline & attention on victims & $\begin{array}{l}\text { Participant 2: "gun laws to become more } \\
\text { appropriate" }\end{array}$ \\
\hline & & $\begin{array}{l}\text { Participant 3: "more attention to cases that are not } \\
\text { high profile" }\end{array}$ \\
\hline & & $\begin{array}{l}\text { Participant 4: "a space where children in elementary } \\
\text { school learn coping mechanisms and alternatives to } \\
\text { gun violence" }\end{array}$ \\
\hline \multirow[t]{7}{*}{$\begin{array}{l}\text { Q3: What political policy(s) would you } \\
\text { like to see reflected to possibly aid } \\
\text { yourself or anyone else in this position? }\end{array}$} & $\begin{array}{l}\text { Demanding resources for } \\
\text { families }\end{array}$ & $\begin{array}{l}\text { Participant 1: Implementing resources that } \\
\text { encourage and make court testimonies for mothers } \\
\text { and families who have been impacted by gun } \\
\text { violence more efficient." }\end{array}$ \\
\hline & & $\begin{array}{l}\text { Participant 2: "More resources to the court system } \\
\text { and the victims' families. " }\end{array}$ \\
\hline & & $\begin{array}{l}\text { Participant 3: "More resources for the family for the } \\
\text { families when child lost from law enforcements, } \\
\text { more forensics test, free lawyers, and mental health } \\
\text { resources for the fathers" }\end{array}$ \\
\hline & $\begin{array}{l}\text { Laws on gun violence } \\
\text { prevention and centered }\end{array}$ & $\begin{array}{l}\text { Participant 4: "prevent guns from getting on the } \\
\text { streets" }\end{array}$ \\
\hline & attention on victims & $\begin{array}{l}\text { Participant 2: "gun laws to become more } \\
\text { appropriate" }\end{array}$ \\
\hline & & $\begin{array}{l}\text { Participant 3: "more attention to cases that are not } \\
\text { high profile" }\end{array}$ \\
\hline & & $\begin{array}{l}\text { Participant 4: "a space where children in elementary } \\
\text { school learn coping mechanisms and alternatives to } \\
\text { gun violence" }\end{array}$ \\
\hline
\end{tabular}


The quantitative results obtained from the selfreported measures demonstrated that B.M.C.G.V. experience compounding levels of post-traumatic stress, complicated grief, and post-traumatic growth.

\subsection{Post-Traumatic Stress}

Findings associated with post-traumatic stress indicated that all Black mothers who lost a child to gun violence in this study reported that it was somewhat true that they avoid things that remind them of their loved ones such as going places they used to go together and looking at their pictures. $(n=4,100 \%)$. 3 out of 4 of the mothers in this study also reported that it was somewhat true they felt cut off or distant from other people since their loved one died - specifically people they used to feel close to such as their family and friends $(n=3$, $75 \%)$.

\subsection{Complicated Grief}

Outcomes related to complicated grief revealed that all mothers reported that they felt a great deal of loneliness since their child has died. $(n=4$, 100\%). Furthermore, 3 out 4 B.M.C.G.V. reported that memories of their child upset them in the last past 7 days $(n=3,75 \%)$.

\subsection{Post-Traumatic Growth}

Results aligning with post-traumatic growth displayed that all Black mothers in this study reported it was mostly true that they learned they were stronger than they originally thought they were after losing a child to gun violence. $(n=4$, 100\%). 3 out of 4 Black mothers in this study stated it is mostly true that they developed a strong religious faith upon losing a child to gun violence. $(n=3,75 \%)$. Additionally, 3 out of 4 Black mothers in this study reported that they found a stronger sense of purpose in life upon losing a child to gun violence $(\mathrm{n}=3,75 \%)$.

\subsection{Depressive Symptomatology}

Black mothers' reports of depressive symptomatology contained a large amount of variation and did not produce any significant results.

\section{Discussion - Policy Recommendations}

The findings of this study that captured posttraumatic stress, complicated grief, and posttraumatic growth among B.M.C.G.V. are consistent with pre-existing literature and hypothesis 1 . Hypothesis 1 indicated that Black Mothers in the Washington DC- Baltimore area who have lost a child to gun violence will exhibit emotional expressions of trauma, grief, and depression. As shown, in the quantitative and qualitative results of this study: the homicidal loss of a child is one of the most disruptive psychological traumas that a mother can experience. $\stackrel{25}{ }$ Post-traumatic stress can be characterized as an experience of distressing oscillation between intrusion and avoidance. ${ }^{21}$ Black mothers reported experiences of avoiding things that remind them of their child is a detailed indicator that exemplifies the post-traumatic stress associated with losing a child to gun violence. Moreover, the post-traumatic stress that B.M.C.G.V. in this study experienced was further marked by feeling distant from their close family members because of the intrusive emotions that these mothers encountered when thinking about their children as homicide victims. Due to the type of death-homicide-which entails suddenness, lack of anticipation, violence, and destruction, a longer grieving interval may be present among Black mothers who lost a child to gun violence. ${ }^{4} \mathrm{It}$ is important to note that all B.M.C.G.V. included in this study lost their child 1-3 years more prior to the start date of this study. Despite this interval of time, all Black mothers in the study reported they experienced constant feelings of loneliness and that memories of their child in the past 7 days upset them. In the midst of these Black mothers 
processing the complicated grief associated with losing a child, some Black mothers sought to reconcile their trauma with their religious beliefs which can strengthen those beliefs, lead to positive spiritual change, shifted priorities, and an appreciation for life post-trauma. $\frac{16}{}$ Hypothesis 2 which predicted that Black Mothers demonstrate high levels of self-sufficient coping mechanisms, post-traumatic growth qualities, and traits of resilience was proven to be true. Post-traumatic growth was a prevalent variable and resilient coping mechanism that allowed mothers to manage the stress associated with the loss. As shown in this study, 3 out 4 of Black mothers reported that it was mostly true that they developed a strong religious faith and found a stronger sense of purpose in life upon losing a child to gun violence. Most notably, all of the mothers in this study reported it was mostly true that they learned they were stronger than they originally thought they were after losing a child to gun violence. Therefore, Black mothers' reported experiences of post-traumatic growth in this study can be seen as a positive psychological change due to the experience and processing of the disaster and its aftermath..$\underline{ }$

The qualitative findings demonstrated that there is a multitude of resilience methods and coping strategies that shape B.M.C.G.V. healing processes. Based on the reported data in this study, Black mothers explained themselves as loving, committed, strong, and unconditionally loving despite their lived experiences of losing a child to gun violence. (See Table 2). This initial finding encouraged Black mothers to speak toward their experiences with coping. Coping is the set of intentional, goal-directed efforts people engage in to minimize the physical, psychological, or social harm of an event or situation. 27 , 28 Black mothers reported coping experiences diverged among two outcomes which were active coping and avoidant coping. Active coping refers to the utilization of psychological or behavioral coping efforts that are characterized by an attempt to use one's resources to deal with a problem situation. ${ }^{29}$ These responses are designed either to change the nature of the stressful situation or event in order to decrease the problematic nature of that situation or event, or to modify how one thinks and feels about it in order to change one's reactions to it. ${ }^{29}$ Avoidance coping involves cognitive and behavioral efforts oriented toward denying, minimizing, or otherwise avoiding dealing directly with stressful demands..$^{30}$ Black mothers reported active coping styles were displayed through themes such as self-love, forgiveness, and faith in god. These active coping strategies were used by Black mothers as a leveraging effort to reframe and manage stressful emotions surrounding losing a child to gun violence. On the contrary, Black mothers' avoidant coping styles in this study were situated on denial, betrayal, and lack of coping. The avoidant coping style's mothers demonstrated were centered on focal points that allowed mothers to dissuade and desist from coping as a way to sustain their psychological distress surrounding losing a child to gun violence. Both of the coping styles mothers demonstrated were effective variables that formulated the policy suggestions that B.M.C.G.V. in this study recommended.

Outcomes regarding Black mothers' policy suggestions can be interpreted through a Black feminist pedagogical lens. A Black feminist pedagogy is a methodology for promoting equality and multiple visions and perspectives that parallel Black women's attempts to be and become recognized as human beings and citizens rather than objects and victims. $\frac{31}{1}$ B.M.C.G.V. in this study's policy recommendations were centered on mothers advocating for equity and restorative laws that valued their experiences as citizens who lost a child to gun violence. Black mothers reported themes detailing that Black mothers were: Demanding resources for families and Laws on gun violence prevention that are centered around victims. The policy recommendations that Black mothers 
in this study provided focusing on garnering more resources to families in the court of law, providing free legal services, and implementing alternatives to gun violence can be viewed as progressive solutions for change that can be adopted by council members and mental health providers in the BaltimoreWashington area.

Taking this into account, the next steps should focus on analyzing how the deliverable policy outcomes that Black mothers reported relating to legal advocacy support and mental health pipelines can be explored as effective buffers to augment the emotional burden of losing a child to gun violence. Furthermore, future research should study posttraumatic growth, complicated grief, posttraumatic stress, and depressive symptoms among B.M.C.G.V. with a larger sample size in order to gain statistically significant results. Lastly, the field of psychology should seek to use intersectional tailored psychometric scales that are attentive to B.M.C.G.V. social identities and lived experiences in order to gain rich and meaningful data on this topic.

\section{Limitations}

This study includes several limitations that should be addressed in future research. For example, given the small sample size of B.M.C.G.V. that were involved in this study, findings should be interpreted with caution. This small sample is not fully representative of the larger population of B.M.C.G.V. in the BaltimoreWashington area therefore the outcomes in this study are not generalizable. Moreover, considering that this study does not include a comparison group to B.M.C.G.V, the findings of this study do not control for external factors that may have also influenced this population's reported outcomes relating to depression, grief, and post-traumatic stress. For example, the high variability within the marital status among B.M.C.G.V in this study may have impacted each mothers' reported outcomes regarding depression, complicated grief, and posttraumatic growth. Additionally, this study was conducted in the midst of the COVID-19 pandemic mothers reported feelings of complicated grief, post-traumatic stress and depressive symptoms may have been heightened due to the global crisis that was occurring during the time this data was assessed.

\section{Conclusions}

This study examined how post-traumatic stress, complicated grief, and depressive symptoms induced from losing a child to gun violence affect Black mothers' methods of resilience, coping strategies, and post-traumatic growth possibilities. Black mothers' experiences with resilience, coping, and posttraumatic growth is an understudied topic that needs to be more thoroughly investigated, understood, and acknowledged as a notable source of scientific inquiry. Evaluating Black mothers' experiential knowledge with losing a child to gun violence is a necessary topic to research considering that the reported outcomes from this population can allow the field of psychology to understand Black motherhood through an informative lens that showcases an array of alternative healing methods. Black mothers' informative and elusive healing methods can serve as vectors of knowledge that can inform legislation surrounding allocating resources to communities in which Black mothers experience the most prevalence of gun violence. By centering on Black mothers' healing experiences, this study aims to leverage these mothers' socially innovative suggestions to encourage clinicians and councilmembers to improve mental health services for the B.M.C.G.V. in the Washington, DCBaltimore city metropolitan region

\section{References}

1. Jones, Cecily. (2008). Caribbean mothers: identity and experience in the UK. Feminist Review. 89. https://doi.org/10.1057/fr.2008.13

2. Beauboeuf-Lafontant, T. (2007). You Have to Show Strength: An Exploration of Gender, Race, and Depression. Gender E Society, 21(1), 28-51. https://doi.org/10.1177/0891243206294108

3. Davidson, D., \& Stahls, H. (2010). Maternal grief: Creating an environment for dialogue. Journal of 
the Motherhood Initiative for Research and

Community Involvement, 1(2).

4. Huggins, C., \& Hinkson, G. (2020). Signs of traumatic grief, lack of justice, magnitude of loss, and signs of resilience following the homicidal loss of their adult child among caribbean black mothers. OMEGA - Journal of Death and Dying, 003022282092101.

https://doi.org/10.1177/0030222820921013

5. Dubisar, A. (2018). Mothers against gun violence and the activist buffer. College English, 80(3), 195.

6. Manove, E. E., Lowe, S. R., Bonumwezi, J., Preston, J., Waters, M.C., \& Rhodes, J. E. (2019)/ Posttraumatic growth in low-income Black mothers who survived Hurricane Katrine. American Journal of Orthopsychiatry, 89(2), 144-158. https://doi.org/10.1037/ort0000398

7. Black women's Health imperative (2017) "Depression in Black Women: How Do You Know If You're Depressed?” Black Women's Health Imperative, 31 July 2017, https://bwhi.org/2017/07/31/depression-blackwomen-know-youre-depressed/

8. Hannays-King, C., Bailey, A., \& Akhtar, M. (2015). Social support and black mothers' bereavement experience of losing a child to gun homicide. Bereavement Care, 34(1), 10-16.

9. Ensink, K., Robertson, B. A., Zissis, C., \& Leger, P. (1997). Post-traumatic stress disorder in children exposed to violence. South African medical journal, 87(11), 1526-1530.

10. Armour, M. (2006). Violent death: Understanding the context of traumatic and stigmatized grief. Journal of Human Behavior in the Social Environment, 14, 53-90. https://doi.org/10.1300/J137v14n0404

11. Bailey, A., Sharma, M., \& Jubin, M. (2013). The mediating role of social support, cognitive appraisal, and quality health care in black mothers' stress-resilience process following loss to gun violence. Violence and victims, 28(2), 233-247.

12. Kristensen, P., Weisaeth, L., \& Heir, T. (2012). Bereavement and mental health after sudden and violent losses: A review. Psychiatry, 76-97.

13. Horowitz, M. J., Siegel, B., Holen, A., Bonanno, G. A., Milbrath, C., \& Stinson, C. H. (2003). Diagnostic criteria for complicated grief disorder.
FOCUS, 1(3), 290-298.

https://doi.org/10.1176/foc.1.3.290

14. Shear, M. K., \& Mulhare, E. (2008). Complicated grief. Psychiatric Annals, 38(10), 0048571320081001-20081010. https://doi.org/10.3928/00485713-20081001-10

15. Burke, L. A., Neimeyer, R. A., \& McDevittMurphy, M. E. (2010). African American Homicide Bereavement: Aspects of Social Support That Predict Complicated Grief, PTSD, and Depression. OMEGA - Journal of Death and Dying, 61(1), 1-24. https://doi.org/10.2190/OM.61.1.a

16. Tedeschi, R. G., \& Calhoun, L. G. (2004). " Posttraumatic growth: Conceptual foundations and empirical evidence". Psychological inquiry, 15(1), 118.

17. Calhoun, L. G., Cann, A., \& Tedeschi, R. G. (2010). The posttraumatic growth model: Sociocultural considerations.

18. Sudman, S., Sirken, M. G., \& Cowan, C. D. (1988). Sampling rare and elusive populations. Science, 240(4855), 991-996.

19. Prigerson, H. G., Maciejewski, P. K., Reynolds III, C. F., Bierhals, A. J., Newsom, J. T., Fasiczka, A., ... \& Miller, M. (1995). Inventory of Complicated Grief: a scale to measure maladaptive symptoms of loss. Psychiatry research, 59(1-2), 6579.

20. Association, American Psychological. "Inventory of Complicated Grief (ICG).” American Psychological Association,American Psychological Association, www.apa.org/pi/about/publications/caregivers/prac tice-settings/assessment/tools/complicated-grief.

21. Weiss D.S. (2007) The Impact of Event Scale: Revised. In: Wilson J.P., Tang C.S. (eds) CrossCultural Assessment of Psychological Trauma and PTSD. International and Cultural Psychology Series. Springer, Boston, MA. https://doi.org/10.1007/978-0-387-70990-1 10

22. Riessman, C. K. (2008). Narrative methods for the human sciences. Sage Publications.

23. Holstein. Varieties of narrative analysis. SAGE Publications.

http://methods.sagepub.com/book/varieties-ofnarrative-analysis

24. Butina, M. (2015). A narrative approach to qualitative inquiry. American Society for Clinical 
Laboratory Science, 28(3), 190-196.

https://doi.org/10.29074/ascls.28.3.190

25. Smith Lee, J. R., Hunter, A. G., Priolli, F., \&

Thornton, V. J. (2020). "Pray that I live to see another day": Religious and spiritual coping with vulnerability to violent injury, violent death, and homicide bereavement among young Black men. Journal of Applied Developmental Psychology, 70, 101180.

https://doi.org/10.1016/j.appdev.2020.101180

26. Dunn, E. C., Solovieff, N., Lowe, S. R., Gallagher, P. J., Chaponis, J., Rosand, J., ... \& Smoller, J. W. (2014). Interaction between genetic variants and exposure to Hurricane Katrina on post-traumatic stress and post-traumatic growth: a prospective analysis of low income adults. Journal of affective disorders, 152, 243-249.

27. Lazarus, R. S., \& Folkman, S. (1999). Stress, appraisal, and coping. Springer. http://www.dawsonera.com/depp/reader/protected /external/AbstractView/S9780826141927

28. Lazarus, R. S. (2006). Stress and emotion: A new synthesis. Springer.

http://www.dawsonera.com/depp/reader/protected /external/AbstractView/S9780826103802

29. Zeidner, M., \& Endler, N. S. (1996). Handbook of coping: Theory, research, applications. New York: Wiley.

30. Holahan, C. J., Moos, R. H., Holahan, C. K., Brennan, P. L., \& Schutte, K. K. (2005). Stress generation, avoidance coping, and depressive symptoms: A 10-year model. Journal of Consulting and Clinical Psychology, 73(4), 658-666. https://doi.org/10.1037/0022-006X.73.4.658

31. Omolade, B. (1987). A Black Feminist Pedagogy. Women's Studies Quarterly, 15(3/4), 32-39. Retrieved July 25, 2021, from http://www.jstor.org/stable/40003434 



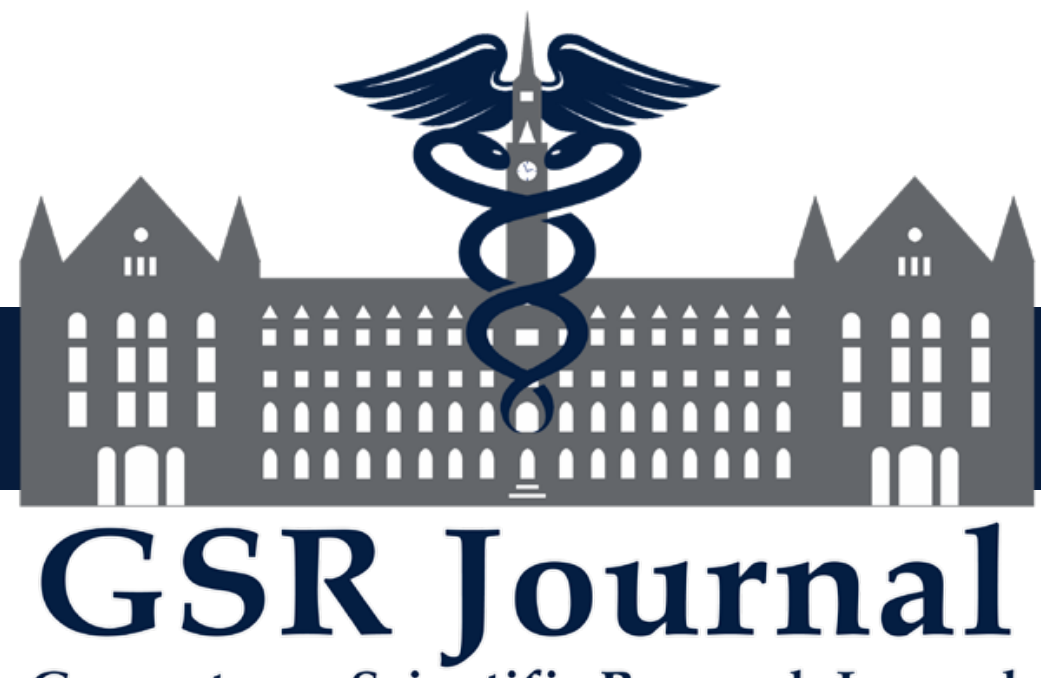

Georgetown Scientific Research Journal 